\title{
MIGRAÇÃO COMO INDICADOR DE DEMOCRACIA, SOBREVIVÊNNCIA ECONÔMICA E NECESSIDADES BÁSICAS ESPECIAIS
}

Ralfo Matos*

Carlos Lobo**

\begin{abstract}
Este trabalho apresenta considerações e evidências sobre a inclusão de populações de estrangeiros em espaços metropolitanos. Parte-se do suposto que a alteridade seja um indicador de "democracia territorial". No Brasil, o Censo 2000 permite identificar certa tolerância étnica em relação ao migrante estrangeiro, como apontado por Mehta para Nova York. São Paulo e Rio de Janeiro, em função do próprio tamanho, abrigam uma grande diversidade de origens nacionais na migração internacional, ainda que exista uma elevada variação nos níveis de renda e no tipo de ocupação.
\end{abstract}

Palavras-Chave: Migração; Democracia territorial; Tolerância étnica.

Há certa obviedade no entendimento do que seja democracia nas sociedades contemporâneas modernas. Tolerância, aceitação dos diferentes, pluralismo, igualdade perante a justiça, respeito às opções individuais somam-se a preceitos republicanos que ao longo do tempo se fundiram ao ideário de governo democrático: separação de poderes e autonomia do Executivo, Judiciário e Legislativo; livre associativismo e direito de voto e acesso a cargos públicos estendido a todos; eleições

\footnotetext{
*Doutor em Demografia. Professor Associado do Departamento de Geografia, Instituto de Geociências da Universidade Federal de Minas Gerais. Endereço: Instituto de Geociências, Universidade Federal de Minas Gerais (UFMG) Av. Antônio Carlos, 6627 - Pampulha - Belo Horizonte - Minas Gerais. E-mail: ralfo@ufmg.br. Belo Horizonte/Brasil.

${ }^{* *}$ Doutor em Geografia. Professor Adjunto do Departamento de Geografia, Instituto de Geociências da Universidade Federal de Minas Gerais. Endereço: Instituto de Geociências, Universidade Federal de Minas Gerais (UFMG) Av. Antônio Carlos, 6627 - Pampulha - Belo Horizonte - Minas Gerais. E-mail: cfflobo@yahoo.com.br. Lagoa Santa - MG/Brasil.
} 
livres e sem a interferência esmagadora do Estado ou da Igreja; garantia da vontade popular em governos laicos, mas com liberdade religiosa e liberdade de expressão.

Contudo, o conceito de democracia pode assumir muitos outros aspectos da vida social e alcançar esferas de civilidade pouco visíveis no âmbito do direito constitucional que vem evoluindo nos últimos 200 anos. Alguns desses aspectos podem nos levar aos princípios elaborados pelos gregos em suas cidades-Estados da Antiguidade, onde a comunhão dos diferentes era tolerada mediante regras de convivência intramuros. As cidades eram o território por excelência das primeiras experiências de resolução de conflitos por meio do debate, assembleias e leis escritas. Com o fim dos muros, surgimento de grandes estados imperiais e mais tarde dos estados nacionais, a noção de democracia incorporou outras acepções mais abrangentes territorialmente, mas todas elas fundadas em atributos caros à vida em sociedade: presença de cidades estratégicas por onde circulavam riquezas e presença de populações economicamente ativas numerosas. Contudo, durante muito tempo, a maioria da população era pobre e os pobres da cidade compunhamse de escravos, campesinos desalojados de suas áreas rurais, imigrantes estrangeiros, enfim, desvalidos da fortuna e sorte, com parcos direitos e muitos deveres, portanto distantes da experiência democrática tal como aquela vivida pelos gregos e alguns povos nas cidades-estados da orla do mediterrâneo na Antiguidade.

A construção de estados democráticos foi e continua sendo uma tarefa complexa, geralmente de corte elitista e só depois mais abrangente socialmente, variável regionalmente, dependendo da força de culturas antigas de cunho despótico, segregacionista e sagrado-fundamentalista. Tudo isso ainda é atual, a despeito dos avanços - nem sempre lineares, nem sempre acelerados - que se desdobraram após a Revolução Americana e a Revolução Francesa no século XVIII. É evidente que o Terror e a guilhotina - que afinal vitimou o próprio Robespierre - ou a escravidão negra nos EUA, que resultou na Guerra da Secessão, estão longe do ideário democrático republicano em termos de cultura civil. Esses eventos, o terror e a guerra, ainda resultavam das forças renitentes do autoritarismo como cultura, ancoradas no militarismo e/ou na velha aristocracia, a se interpor no difícil caminho do aprofundamento resolutivo da democracia 
nos países ou nos fóruns internacionais nos quais o "humanismo"1 tenta ser sufragado nas assembleias das nações em busca da paz.

Diante de certas dicotomias teorizadas há tanto tempo, tais como guerra e paz, democracia e ditadura, economia e cultura, pode-se arguir sobre as vantagens do pensamento multi/transdisciplinar inscrito na valorização de práticas democráticas desenvolvidas nos espaços de vida, nos territórios das pessoas e da sociedade. Nesse sentido, é pertinente repensar conceitualmente as chamadas necessidades básicas, comumente restritas a uma cesta de bens econômicos, revestindo-as das dimensões da cidadania e da cultura de pertencimento que o humanismo celebra. Caberia incluir entre as necessidades básicas os direitos elementares, a liberdade civil, a democracia deliberativa ${ }^{2}$, enfim, a confiança estendida das pessoas, parentes e familiares até aos vizinhos e comunidades urbanas solidarizadas pela noção de civismo.

As reflexões que se seguem têm como pano de fundo as observações supracitadas, mas sem explorá-las in totum. Procuram apenas discutir e exibir algumas evidências empíricas a favor da inclusão relativa de populações de não naturais/estrangeiros em espaços urbanos. Vale dizer, territórios especiais nos quais a democracia deu seus primeiros passos. Malgrado a complexidade que interfere nas maiores cidades da atualidade, seja por imposições ditadas pela ordem econômica transnacional, seja por determinadas idiossincrasias identitárias e culturais, seja pelos movimentos que difundem a premissa cosmopolita da igualdade e liberdade como pré-requisitos do desenvolvimento humano, é possível discernir os imigrantes como atores específicos que participam vivamente da dinâmica social e econômica de grandes metrópoles. Caracterizá-los, identificá-los e enumerá-los pode ser metodologicamente um recurso para aferir a maior ou menor presença do ar de liberdade que se respira nessas cidades. Isso pode ser também um indicador de democracia, uma forma de examinar compartimentos intrincados que perpassam a ideia de tolerância e pluralidade.

\footnotetext{
${ }^{1}$ Sócrates é considerado o fundador do pensamento humanista na filosofia. Na renascença italiana, o humanismo voltou a ser debatido e ganhou expressão no mundo das ideias com o aprofundamento da discussão do conceito "liberdade" por meio de um novo entendimento: liberdade como valorização do cidadão frente ao indivíduo; e liberdade como ação coletiva de cidadãos na cena pública mediante efetiva participação nos negócios da cidade. O resgate teórico de noções do humanismo cívico e a tentativa de adaptá-lo a situações do Brasil contemporâneo se apresenta em BIGNOTTO, N. "Problemas atuais da teoria republicana".

${ }^{2}$ Ver entre outros: HABERMAS, Jürgen. "Três modelos normativos de democracia"; WERLE, Denilson Luís. "Democracia Deliberativa e os Limites da Razão Pública".
} 


\section{O drama dos migrantes e seus direitos em discussão}

O século XX foi, de fato, recortado por períodos sombrios de migrações forçadas por violência, guerras e catástrofes, algumas motivadas por fatores econômicos, colapso de impérios coloniais, limpeza étnica e intolerância. A ideia de uma comunidade internacional unida na diversidade parecia tornar-se distante, a despeito dos avanços no campo dos direitos humanos e das conquistas tecnológicas que melhoraram as condições de vida de crianças, jovens e idosos. As crises econômicas, conflitos e guerras do século fizeram surgir o drama dos refugiados. Milhões de pessoas erraram sem destino certo pela Europa, Ásia, África e Américas, em busca de emprego, moradia e condições mínimas de vida humana, geralmente estabelecendo redes sociais que lhes devolviam parcialmente o sentimento de pertença. Sem essas redes, dificilmente suportariam as adversidades que enfrentaram pela perda de referenciais culturais e territoriais e pela discriminação e perseguição xenofóbica.

Houve avanços nos direitos dos imigrantes e de suas famílias, mas essa é uma questão espinhosa porque, além das injunções econômicas e sociais, depende das armaduras jurídicas diferenciadas de cada Estadonação. As proclamações das Nações Unidas ao final da II Guerra Mundial foram um passo importante, ao acentuar os valores de cooperação, solidariedade, combate ao racismo e xenofobia. Contudo, tratou de modo insuficiente o problema dos migrantes e refugiados, não obstante os méritos da comissão encarregada de elaborar princípios internacionais sobre direitos humanos como assunto prioritário, trabalho que resultou na Declaração Universal dos Direitos Humanos em 1948. Essa declaração inspirou-se na Declaração dos Direitos do Homem e do Cidadão decorrente da Revolução Francesa (1789), mas tanto uma quanto a outra eram desprovidas de instrumentos capazes de assegurar o cumprimento de suas diretrizes. Mas ainda são documentos essenciais porque reforçam a defesa do indivíduo, incentivam a democracia e fazem objeção aos Estados tirânicos, despóticos e absolutistas/totalitários. ${ }^{3}$

O direito de ir e vir, e os direitos de nacionalidade e de regresso ao país de origem foram afirmados ao final do texto da ONU, mas sem destoar

\footnotetext{
${ }^{3}$ Sobre esse tema ver entre outros: BAGANHA, Maria loannis. "A cada sul o seu norte: dinâmicas migratórias em Portugal"; BELLI, Benoni. A politização dos direitos humanos; BOBBIO, Norberto. A era dos direitos; BRITO, Fausto. A ruptura dos direitos humanos na filosofia política de Hannah Arendt; CANOTILHO, Joaquim Gomes (org.). Direitos Humanos, Estrangeiros, Comunidades Migrantes e Minorias; CASTRO, Mary Garcia. "Migrações internacionais e direitos humanos e o aporte do reconhecimento"; REIS, Rossana Rocha. "Soberania, Direitos humanos e migrações internacionais".
} 
do princípio da soberania nacional dos países signatários, onde afinal seriam escritas as leis que de fato regulariam os movimentos das populações de estrangeiros e nacionais. Todavia, abria-se espaço para o florescimento e avanço do direito internacional. Vários textos foram aprovados, na ONU, na OIT e em outros fóruns, sob a forma de "convenções" e/ou recomendações, relacionadas aos crimes de genocídio, discriminação de apátridas, refugiados e trabalhadores migrantes. Servem de exemplo: a Convenção de Prevenção e Punição dos Crimes de Genocídio (1948), a Convenção da Imigração para o Trabalho (1949), a Convenção de Genebra sobre o Status de Refugiado (1951), a Convenção Relativa aos Apátridas (1954), a Convenção de Prevenção de Formação de Apátridas (1961), a Convenção dos Trabalhadores Imigrantes (1975), a Convenção Internacional sobre a Proteção dos Direitos de Todos os Trabalhadores Migrantes e dos Membros das suas Famílias (1990)4ㄹ a Declaração de Cuenca de 2008, entre outras.

A Convenção Internacional sobre a Proteção dos Direitos de Todos os Trabalhadores Migrantes e dos Membros das suas Famílias, que entrou em vigor só em julho de 2003, deixa claro, em seu preâmbulo, a extensão do problema migratório em muitos estados diante da vulnerabilidade social dessas populações frente aos serviços oferecidos nas áreas receptoras e da falta de proteção internacional adequada às comunidades forçadas à dispersão. A insegurança e precariedade no trabalho são comuns entre os clandestinos, indocumentados (não raro resultantes do tráfico internacional de trabalhadores), condição que acaba por disparar a xenofobia e intolerância dos nacionais diante da "chamada" concorrência desleal dos imigrantes. A Convenção aponta o déficit de direitos humanos fundamentais entre os trabalhadores migrantes, a necessidade de concessão de direitos adicionais a essas comunidades, frequentemente em situação irregular. A regularização talvez encorajasse

\footnotetext{
${ }^{4}$ Essa relação pode ser bem mais extensa se incorporar as ações e recomendações resultantes das diversas comissões da ONU e da OIT, que produziram documentos como: o Pacto Internacional sobre os Direitos Económicos, Sociais e Culturais; o Pacto Internacional sobre os Direitos Civis e Políticos; a Convenção Internacional sobre a Eliminação de Todas as Formas de Discriminação Racial; a Convenção sobre a Eliminação de Todas as Formas de Discriminação contra as Mulheres; a Convenção sobre os Direitos da Criança; a Convenção relativa aos Trabalhadores Migrantes (OIT, n. 97), a Convenção relativa às Migrações em Condições Abusivas e à Promoção da Igualdade de Oportunidades e de Tratamento dos Trabalhadores Migrantes (n.143); a Recomendação relativa à Migração para o Emprego (n. 86$)$; a Recomendação relativa aos Trabalhadores Migrantes (n.․․ 151); a Convenção sobre Trabalho Forçado ou Obrigatório (n.ำ29); a Convenção sobre a Abolição do Trabalho Forçado (n. - 105); a Convenção relativa à Luta contra a Discriminação no Campo do Ensino, Ciência e a Cultura (ONU); a Convenção contra a Tortura e Outras Penas ou Tratamentos Cruéis, Desumanos ou Degradantes; as Convenções sobre a Escravatura, entre outras.
} 
os empregadores a respeitar e a aplicar as leis internacionais sobre os migrantes.

Sobre o mesmo tema, vários pontos são arrolados por Maria Manuela Mendes em seus comentários sobre o livro de Joaquim Gomes Canotilho, o qual aprofunda a questão dos direitos humanos confrontados com a situação das comunidades de migrantes. Entre os destaques indicados pela autora recolhemos alguns trechos que convergem com o ideário de democratização internacional por meio da aceitação dos diferentes e extensão de direitos aos trabalhadores migrantes, certamente na perspectiva de alargar o conceito de pátria para além das fronteiras dos Estados nacionais como tantos almejam há bastante tempo.

Como norma de conduta de Estados, Canotilho ${ }^{5}$ assinala a importância de regras de convivência objetiva e subjetiva de pessoas e povos diferentes, nas quais compareçam, ao lado dos artigos constantes na Declaração da ONU de 1948, o direito dos migrantes à liberdade e segurança social (questão grave, uma vez que sem essa proteção debilitase a força de trabalho dos imigrantes); o direito de acesso ao direito e a garantias processuais; a proibição de expulsão arbitrária; o direito de casar e de constituir família; o respeito pela vida privada e familiar; o direito ao reagrupamento familiar; o direito à educação, à informação e acesso aos meios de comunicação social; o direito à propriedade privada; o direito a condições de trabalho socialmente dignificantes; o direito à sindicalização e à participação na vida da empresa; o direito à segurança social; o direito a cuidados médicos e ao subsídio de doença (muito debatidos em fóruns internacionais); o direito à moradia. Sobre esse último, convém informar que, em outubro de 2010, foi examinada na ONU a legislação internacional existente sobre a matéria e elaborado um relatório que expõe as dificuldades de acesso a moradias condignas vividas por imigrantes homens, mulheres e crianças alocados na economia informal. O relatório propõe uma série de recomendações práticas aos governos no item direito a moradia adequada.

Os esforços internacionais para a proteção dos migrantes, particularmente os irregulares e destituídos de direitos, vêm sendo empreendidos no mundo inteiro, inclusive nos EUA após 11 de setembro de 2001. Contudo, esse é um assunto complexo e cheio de arestas decorrentes dos próprios direitos de soberania dos Estados vis-à-vis os direitos relativos ao indivíduo e aos grupos étnicos provenientes de

\footnotetext{
${ }^{5}$ CANOTILHO, op. cit.
} 
correntes migratórias novas e antigas. Aqui pesam muito as posições políticas e ideológicas ${ }^{6}$ dos Estados e sociedades. A despeito da liberdade de circulação do capital nas economias de mercado e da evidente necessidade de mão-de-obra em uma série de atividades econômicas em que há desinteresse ou carência de trabalhadores nativos, a livre circulação de trabalhadores migrantes ainda gera controvérsias entre os países.

No século $X X$, quando a hegemonia econômica americana se definiu, os EUA foram a principal área de recepção de migrantes das mais diversas origens. Nova York, desde o século XIX, se fez com base na contribuição da força de trabalho de imigrantes de diversos continentes, o que a tornou maior que qualquer cidade até perto de 1960, além de próspera e cosmopolita. A sudeste, Miami foi construída e cresceu expressivamente em poucas décadas a partir do trabalho de milhões de latino-americanos. Projeções das Nações Unidas indicam que os EUA irão conviver com um saldo migratório de 450 mil pessoas por ano durante o período 1990-2025, só menor do que o da década de 1980 quando o fluxo anual chegou a 750 mil pessoas. Não obstante as barreiras levantadas na fronteira sul com o México, considerando os atuais níveis de fecundidade dos americanos e as tendências estimadas de saldo migratório anual, a maioria da população dos EUA será composta de imigrantes e seus descendentes procedentes do mundo não anglófilo. Afinal, a história ensina que nenhum país próspero pode assistir ao declínio de sua força de trabalho sem uma reposição com imigrantes de nações mais pobres, mesmo tendo em conta que imigrantes qualificados sejam preferidos nos processos seletivos denominados fuga de cérebros. ${ }^{7}$

\footnotetext{
${ }^{6}$ A declaração de Cuenca (de abril de 2008) ressalta que mais de 30 milhões de pessoas têm migrado dentro e fora da América Latina e Caribe, o que representa cerca de $5 \%$ da população dessa parte do continente. Em países como Bolívia, El Salvador, Haiti e Nicarágua os emigrantes ultrapassam os $20 \%$ da população total. Em 2007 os dados registravam que os emigrantes enviaram aos seus países de origem mais de 67 bilhões de dólares. Além disso, perto de cinco milhões de pessoas vêm sendo deslocadas dentro de seus próprios países em razão de perseguições políticas, violência e conflitos armados.

7 Por outro lado as remessas dos migrantes aos países de origem têm sido relevantes para seus familiares e sustentado algumas economias locais, a exemplo dos dólares americanos enviados a várias cidades do México. Desde os anos de 1960 as transferências de divisas dos migrantes acompanham os grandes fluxos internacionais. Após 1974, momento em que os fluxos europeus sul-norte começaram a declinar, cresceram fortemente as transferências para o Egito, lêmen, Sudão, Jordânia, Síria, Índia, Paquistão, Coreia do Sul, Bangladesh e Filipinas. A maioria desses recursos vinha de migrantes residentes em países exportadores de petróleo. Após 1974, as transferências parecem ir para investimentos nos países de origem dos migrantes, embora os filhos das primeiras gerações de emigrantes já se sintam desobrigados dessa tarefa. Cf. MATOS, Ralfo. Geografia da População, p. 90.
} 


\section{A contribuição da migração nas grandes cidades}

Estudos internacionais discutem há várias décadas os impactos causados pelos migrantes nas áreas de destino, já que o senso comum e a voz conservadora das elites e de políticos não veem com bons olhos a "invasão" de suas grandes cidades por hordas de gente pobre, desempregada, não qualificada, desconhecedora dos hábitos e costumes do lugar, "disponível" para cometer ilícitos e atividades criminosas, enfim uma gente diferente, suspeita por definição. Boa parte dos estudos, entretanto, conclui em direção oposta e contraria as teses preconceituosas e racistas que alimentam surtos históricos de xenofobia em várias partes do mundo rico.

Na verdade, a maioria dos imigrantes ocupa postos de trabalho mal remunerados nas áreas receptoras, mas gradativamente melhoram sua situação ocupacional e de renda. Frequentemente contribuem fortemente para o desenvolvimento das cidades que os recebem e, a despeito do começo difícil, em pouco tempo se adaptam e sentem-se "beneficiados pela sorte" quando se deparam com as condições de vida de amigos e familiares que permaneceram em seus lugares de origem.

Essa evidência, discutida em vários trabalhos internacionais, foi objeto de trabalhos conduzidos pelo IPEA no Brasil a partir dos anos de 1970. Martine e Peliano, quando analisaram as implicações dos diferenciais entre as populações migrante e não migrante, concluíram que: apesar da ausência de diferenciais significativos entre essas duas subpopulações nos estratos de baixa renda das metrópoles, ao se focalizar os migrantes ocupados no mercado de trabalho e com mais tempo de residência, seus níveis de rendimento tendiam a superar os dos não migrantes, como se já estivessem ultrapassado "os obstáculos à mobilidade socioeconômica. Em suma, fica amplamente caracterizada a melhoria progressiva na situação sócioeconômica da população migrante à medida que aumenta sua permanência no local de destino ${ }^{\prime \prime}$. Contudo, as evidências também sugeriam que um número expressivo de jovens migrantes mal sucedidos retornava a suas áreas de origem e os que ficavam tinham de suportar as adversidades dos processos de seletividade da migração. Com isso, mesmo que os números apontassem a existência de subgrupos não muito numerosos que desfrutavam de condições privilegiadas, no âmbito dos

${ }^{8}$ MARTINE, George; PELIANO, José Carlos. "Diferenciais Migratórios: Resultados e Implicações". 
grandes números, conviria ter cuidado ao se concluir que a situação dos imigrantes melhora claramente com o tempo de residência.

Em 1980, o texto mais conhecido de George Martine ${ }^{9}$ resume as questões abordadas no trabalho anterior quando pergunta se os migrantes nas grandes cidades viviam um processo de adaptação exitosa ou, dados os níveis de exclusão do mercado de trabalho, só sobreviviam os mais fortes? Apesar dos problemas relacionados às limitações dos dados demográficos para responder questões teóricas não triviais, suas conclusões ressaltam que os estudos comparativos de subgrupos de migrantes indicavam notável convergência com outros estudos sobre a melhoria das condições de vida do migrante à medida que permaneça mais tempo residindo na área urbana de destino. Contudo, um exame mais meticuloso adverte para pelo menos duas interpretações. A primeira diz respeito à adaptação progressiva do migrante nas áreas de recepção a ponto de equipará-lo com o nãomigrante. A segunda sugere a sobrevivência dos mais aptos, ou seja, diante da evasão das levas de migrantes que chegam anualmente às grandes cidades, um filtro seletivo atuaria no mercado de trabalho incorporando os mais capacitados para o trabalho. No caso do imigrante internacional há também filtros seletivos, mas a volta ao país de origem é, evidentemente, muito mais difícil. E isso faz com que o amparo das redes sociais da migração (que articulam países de origem e destino) seja mais necessário.

Vários autores, que se debruçaram posteriormente sobre a mesma questão, concluíram que a migração, ao longo do tempo, representa de fato um ganho para as atividades econômicas existentes nos lugares de destino e não o contrário, como muitos pensavam até os anos de 1970. Martine reafirma essa conclusão, quando descarta teses neoclássicas que propõem ser a migração, basicamente, um meio de equilibrar salários desiguais regionalmente. As migrações internas redistribuem, há muito tempo, a população no espaço nacional, especialmente entre cidades, redinamizando a urbanização e o crescimento demográfico. Entre 1960 e 1980, por exemplo, houve no Brasil um incremento de cerca de 50 milhões de pessoas nas áreas urbanas brasileiras, momento em que o êxodo rural respondeu por quase 28 milhões de pessoas. ${ }^{10} \mathrm{Em}$ termos de migrações externas há conclusões similares, embora obstáculos relacionados ao idioma, cor, religião, cultura e distância tornem mais difíceis o processo de adaptação ao país receptor.

\footnotetext{
${ }^{9}$ MARTINE, George. "Adaptação dos migrantes ou sobrevivência dos mais fortes?".

${ }^{10}$ MARTINE, George et alii. "A urbanização no Brasil: retrospectiva, componentes e perspectivas".
} 


\section{O exemplo recente de Nova York e a democracia balizada pela tolerância e pela contribuição econômica do imigrante ${ }^{11}$}

Suketu Mehta - morador de Nova York e autor de estudos sobre grandes cidades e sobre o multiculturalismo em metrópoles americanas - analisa a situação atual do maior símbolo territorial do capitalismo mundial, a metrópole nova-iorquina. Apesar dos sucessivos momentos de medo e insegurança após o ataque às torres do World Trade Center em 2001, o autor afirma que a diversidade demográfica continua predominante na cidade. De cada três moradores dois são imigrantes ou filhos de imigrantes. A tolerância étnica testemunhada por Mehta desde a infância prevalece até hoje, a despeito de Nova York estar entre as mais desiguais cidades do mundo, como atestam dados recentes sobre renda dos estratos mais ricos e mais pobres da população. O que explicaria então tanta preferência pela cidade de povos de todas as latitudes?

Seu relato sugere que a resposta estaria no âmbito da experiência sociocultural dos habitantes da região. Os imigrantes que chegam sempre encontram apoio de pessoas de sua comunidade de origem e se ocupam na grande rede de serviços que a cidade oferece: cada um encontra seu lugar, mesmo se forem migrantes clandestinos. Nova York, com gente procedente de cerca de 180 países, diferentemente de outros grandes centros urbanos europeus, absorve essa população e depende dela economicamente, como afirma o prefeito Michael Bloomberg. A densa cidade, com mais de oito milhões de habitantes centraliza uma área metropolitana de cerca de 22 milhões de habitantes, possui o condado mais diversificado etnicamente do país, o Queens, onde mais da metade dos habitantes sequer fala inglês, algo sem paralelo nos EUA.

O crescimento da população imigrante na cidade alcançou 38\% no período de 1990/2000, à custa principalmente de dominicanos, italianos e mexicanos. Nos últimos anos, os 800 mil novos moradores da metrópole indicam que as taxas de crescimento da imigração voltaram a crescer, uma vez superada a crise imobiliária e econômica que se abateu imediatamente sobre Manhathan após 2001. Mesmo tendo em conta a desconfiança e medo, ao lado das medidas adotadas de controle e de restrição à imigração, o autor é enfático ao dizer que os imigrantes salvaram a cidade. Deram-lhe vitalidade e impediram-na de tornar-se segregada e despovoada. Investiram nas escolas e nos serviços,

11 Parte das considerações dos quatro parágrafos subsequentes baseia-se em METHA, Suketu.

"Cidade Nua". 
rejuvenesceram a população e não abandonaram a cidade como tantos americanos de classe média o fizeram após setembro de 2001. Enfim, nos 10 últimos anos, a cidade revela-se como a preferida de todos em termos de moradia.

Como se explica esse fenômeno? Metha sugere que fatores associados a tolerância e os numerosos espaços de pertença existentes na cidade explicam parte da questão e entende que compreender o que torna Nova York tão atraente ajudaria a explicar a situação de outras grandes metrópoles mundiais que vivem situação distinta. $\mathrm{O}$ autor acredita que megacidades como Bombaim, Lagos, Jacarta ou São Paulo se inscreveriam num tipo de territorialidade urbana com características próprias em termos de receptividade de imigrantes; enquanto Londres, Nova York, Paris, Sydney, Toronto, entre outras, se inscreveriam em outro perfil de metrópoles detentoras de muitos imigrantes. Nesse grupo, Nova York seria a joia da coroa.

Essa classificação em dois grupos seria adequada? Há fatores que poderiam ser mais bem explorados para estabelecer outras tipologias? Essas são perguntas de difícil resposta que o autor não enfrentou e continuarão desafiando os analistas por muito tempo. Categorias como cidades pólos, cidades mundiais, grandes núcleos urbanos de pobreza, megacidades orientais ou ocidentais podem auxiliar no aprofundamento desse tipo de pesquisa, mas há mais questões a serem investigadas. Os fatos sugerem que formas comportamentais associadas ao exercício da tolerância podem ser valiosas nesse tipo de investigação, que levem em conta, por exemplo: i) a alteridade exercida nos milhões de encontros difusos nos bares, praças e residências estimulam a tolerância; ii) o pluralismo representado pela grande quantidade de comunidades étnicas (distantes de suas áreas de origem frequentemente mergulhadas em conflitos inter-raciais) também contribuem para uma espécie de cosmopolitismo humanista. Tudo isso, somado cumulativamente ao longo do tempo, deve favorecer a solução de conflitos, mesmo em grandes cidades distantes do paradigma das pequenas cidades-estados da antiga democracia grega.

De toda forma, parece que megacidades povoadas por grande número de imigrantes provenientes de muitos países do mundo estariam indicando maior ou menor grau de expressões virtuosas de "democracia territorial"12 na vida urbana moderna. Como se situa o Brasil diante dessa

\footnotetext{
${ }^{12}$ MATOS, Ralfo. "Notas sobre democracia territorial e espaços urbanos dispersos".
} 
perspectiva? As grandes metrópoles do país diferem muito do exemplo de Nova York?

\section{Grandes metrópoles brasileiras e imigração estrangeira}

O Brasil, assim como os EUA, é um território onde historicamente a contribuição do imigrante externo foi essencial para a formação da nação e para a subsequente expansão urbano-industrial a partir de fins do séc. XIX. Trata-se de um país de populações mestiças de expressão demográfica notável, mesmo que à custa de acasalamentos forçados ou amistosos de homens brancos europeus com índias e africanas cativas a partir do século XVI, o que difere da colonização inglesa no Novo Mundo, onde a mistura "interracial" foi bem menor. Depois da Independência (1822) a elite brasileira pôs em marcha o projeto eugenista de branqueamento da população brasileira por meio da atração de trabalhadores europeus. A tradição da miscigenação passou a incorporar um número maior de etnias.

Malgrado os séculos de colonização, monarquia absolutista e autoritarismo militar, o Brasil, desde os anos de 1950, poderia dispensar a contribuição de mão-de-obra estrangeira com o intuito de preencher seus "vazios demográficos", como fizera por mais de 100 anos. Poderia, inclusive, rejeitar imigrantes estrangeiros dando azos às tendências conservadoras xenófobas do "entre guerras" que alimentaram políticas populacionais baseadas no regime de "cotas". Entretanto isso não prosperou por diversos motivos, alguns óbvios (proximidade cultural com Europa e EUA), outros ideológicos e humanitários (diante da expansão do comunismo internacional e do formidável aumento de refugiados de guerra na Europa e no resto do mundo) e outros não tão óbvios se considerarmos, na segunda metade do século, o término dos governos militares em 1985 e a aprovação da Constituição de 1988. Embora a migração estrangeira seja também objeto de preocupação dos governos democráticos dos últimos 25 anos, há dados que revelam tendências de aceitação de imigrantes que ultrapassam o sentimento meramente humanitário e, talvez, indiquem uma perspectiva humanista na direção de uma democracia territorial internacional fundada em uma espécie de ecumenismo interétnico.

Os dados do Censo 2000 mostram que o número e origem diversificada de imigrantes externos variam com o tamanho, localização e função urbana das principais regiões metropolitanas (RMs) do país. Em ordem decrescente, essas metrópoles ostentavam os seguintes totais 
relativos a imigrantes nascidos fora do Brasil: a RM de São Paulo (RMSP), 13.599 imigrantes naturais de mais de 66 países; a RM do Rio de Janeiro $(\mathrm{RMRJ}), 5.962$ imigrantes nascidos em mais de 44 países; o Distrito Federal, 1.372 imigrantes nascidos em mais de 38 países; a Região Metropolitana de Salvador, 891 imigrantes naturais de cerca de 34 países; a Região Metropolitana de Fortaleza, com 449 estrangeiros naturais de mais de 18 países.

Fica evidente que as maiores metrópoles (RMs de São Paulo e Rio de Janeiro) destacam-se em relação às demais RMs do país. O maior tamanho de áreas urbanas constitui um dos fatores que explica o elevado número de imigrantes provenientes de uma maior diversidade de países. Rio e São Paulo são espaços de larga tradição histórica de imigração estrangeira e isso também explica os números do Censo, da mesma forma que o fator distância interfere na preferência dos imigrantes entre uma ou outra metrópole, e os países integrantes do Mercosul ilustram essa assertiva.

O exame da diversidade das nacionalidades e etnias dos imigrantes deve ajudar a explicar melhor o grau de tolerância e receptividade dos imigrantes nas metrópoles do Rio de Janeiro e São Paulo, mesmo tendo em vista a hostilidade relativa que existe em cada uma delas. Os dados expostos na Tabela 1 deixam explícitas as diferenças existentes entre as duas metrópoles e permite extrair as seguintes conclusões, se recortadas as 20 principais nacionalidade de origem: a) na população de imigrantes da RMSP, a maioria dos fluxos refere-se a países integrantes de quatro continentes: da América do Sul sobressaem os bolivianos, argentinos, peruanos, paraguaios e chilenos (4.538 pessoas); da Ásia destacamse os japoneses, chineses e coreanos (2.434); da Europa e Oriente Médio são majoritários os franceses, portugueses, alemães, espanhóis, italianos, libaneses e britânicos (2.333); da América do Norte vieram 742 estadunidenses; b) No caso do Rio de Janeiro, também predominam os latino-americanos, conforme a ordem que se segue: 1.591 argentinos, colombianos, bolivianos, chilenos, equatorianos, venezuelanos e cubanos; 1.322 pessoas nascidas na França, Portugal, Alemanha, Itália, Grã Bretanha, Espanha e Suíça; 819 imigrantes procedentes de Angola e de outros países africanos; 517 americanos dos EUA; e 338 pessoas que vieram da China e do Japão. 
os africanos, diferentemente do Rio, é menor a participação relativa no total. Na RM do Rio de Janeiro são muito significativos os sul-americanos e europeus, a maior parte deles ocupados no comércio e serviços, e africanos (sobretudo angolanos).

Os diferenciais por renda e ocupação, como proxi das condições de vida, auxiliam a caracterização dos imigrantes tendo em conta a origem e o tipo de trabalho que encontram nas duas maiores metrópoles do país. A ocupação exercida é um indicador da maior ou menor inserção do imigrante na economia brasileira, mesmo que a maioria deles esteja alocada em trabalhos braçais e de baixa remuneração; em alguns casos submetidos a privação de direitos, mesmo que usufruindo de melhores condições de vida do que as de seus países de origem. O que nos dizem os dados da Tabela 2, especialmente se comparados com a Tabela 1 ?

Enumerando as principais conclusões pode-se dizer, em primeiro lugar, que há uma grande disparidade entre os números relativos aos totais das duas tabelas. Na Região Metropoitana de São Paulo (RMSP) perto de 1/2 dos imigrantes internacionais $(52,19 \%)$ não estavam entre os que declararam ocupação e renda na última semana da data do Censo, enquanto na RMSP essa proporção chega perto dos 2/3 (61,58\%). O que essa diferença indica? Sugerimos três respostas: i) é natural que parte da população imigrante não esteja ainda incorporada no mercado de trabalho ou ainda esteja em busca de trabalho fixo na semana anterior ao censo (talvez até $20 \%$ do total de imigrantes); ii) parte dos imigrantes é composta por crianças, cônjuges e idosos que não auferem renda e vieram acompanhando os adultos efetivamente ocupados (talvez 30\% do total); iii) parte dos imigrantes são trabalhadores ilegais (clandestinos e indocumentados) cuja ocupação é omitida por diversas razões, embora a nacionalidade seja declarada nos levantamentos censitários (50\% do total?).

Outra conclusão muito explícita diz respeito à maior proporção dos que declararam renda e ocupação entre os imigrantes naturais de regiões com as quais o Brasil mantém relações de intercâmbio internacional há muito tempo, como Europa e EUA. Observe-se, inclusive, que a grande maioria dos que auferem as maiores rendas e ocupam altos no mercado de trabalho ("gerentes e dirigentes de empresas") são europeus $(61,76$ s.m.) e estadunidenses (48,01 s. m.). Entre os sul-americanos são os argentinos que mais se destacam (dados não mostrados).

Essa última evidência reforça uma conclusão mais específica derivada do que denominamos seletividade pela origem. Por exemplo, 
entre os "trabalhadores dos serviços e do comércio" as remunerações médias variam, em ordem decrescente, conforme as seguintes origens: EUA, Europa, Ásia (especialmente chineses). Com rendimentos bem menores comparecem em sequencia os americanos do sul e africanos. Já entre o conjunto de "trabalhadores da produção de bens e serviços industriais", ocupação de menor remuneração que a classe anterior (média de 3,49 s. m.), a presença dos imigrantes nascidos na América do Sul é quase exclusiva (Tabela 2).

Tabela 2

Imigrantes internacionais não brasileiros residentes nas RMSP e RMRJ segundo ocupação profissional, renda média em salários mínimos (s.m.) e origem continental - 2000

\begin{tabular}{|c|c|c|c|c|c|c|c|c|c|c|c|c|c|}
\hline \multirow{3}{*}{ RMs } & \multirow{3}{*}{ Ocupaçoes } & \multicolumn{12}{|c|}{ Imigrantes não brasileiros distribuidos pelos continentes de origem } \\
\hline & & \multicolumn{2}{|c|}{ América do Sul } & \multicolumn{2}{|c|}{ América do Norte } & \multicolumn{2}{|c|}{ Europa } & \multicolumn{2}{|c|}{ África } & \multicolumn{2}{|c|}{ Ásia } & \multicolumn{2}{|c|}{ Outros } \\
\hline & & No & Renda & No & Renda & No & Renda & No & Renda & No & Renda & No & Renda \\
\hline \multirow{7}{*}{$\sum_{\propto}^{n}$} & Membros do poder público, dirigentes de empresas, gerentes & 305 & 32,21 & 137 & 48,01 & 724 & 61,76 & 13 & 9,93 & 278 & 20,63 & 60 & 47,73 \\
\hline & Trabalhadores dos serviços e do comércio & 760 & 8,41 & 178 & 32,84 & 501 & 25,79 & 86 & 4,07 & 834 & 14,87 & 95 & 17,64 \\
\hline & Técnicos de nível médio & 73 & 11,67 & 23 & 37,05 & 170 & 20,42 & 33 & 5,87 & 185 & 19,22 & 8 & 2,32 \\
\hline & Trabalhadores de serviços administrativos & 77 & 7,06 & 11 & 3,97 & 36 & 31,13 & 0 & $\mathrm{xxx}$ & 65 & 24,58 & 0 & $\mathrm{xxx}$ \\
\hline & Trabalhadores agropecuários, florestais, caça e pesca & 56 & 3,53 & 0 & $x x x$ & 0 & $x x x$ & 0 & $x x x$ & 38 & 5,02 & 0 & $x x x$ \\
\hline & Trabalhadores da produção de bens e serviços industriais & 1.294 & 3,49 & 0 & $x x x$ & 40 & 13,73 & 0 & $x x x$ & 49 & 4,15 & 0 & $x \mathrm{xx}$ \\
\hline & Trabalhadores de reparação e manutenção & 9 & 2,98 & 0 & $x x x$ & 23 & 40,77 & 12 & 3,31 & 8 & 5,30 & 0 & $x \mathrm{xx}$ \\
\hline Total & & 2.574 & & 349 & & 1.495 & & 144 & 23 & & & 163 & \\
\hline \multirow{7}{*}{$\sum_{\propto}^{\widetilde{\alpha}}$} & Membros do poder público, dirigentes de empresas, gerentes & 131 & 26,10 & 92 & 49,97 & 191 & 37,81 & 0 & $x x x$ & 85 & 13,01 & 0 & $\mathrm{xxx}$ \\
\hline & Trabalhadores dos serviços e do comércio & 413 & 15,02 & 97 & 29,24 & 257 & 20,18 & 107 & 7,71 & 94 & 23,43 & 18 & 6,54 \\
\hline & Técnicos de nível médio & 99 & 18,27 & 12 & 13,25 & 85 & 15,56 & 16 & 3,15 & 19 & 34,26 & 19 & 8,66 \\
\hline & Trabalhadores de serviços administrativos & 28 & 7,90 & 0 & $\mathrm{xxx}$ & 27 & 38,82 & 21 & 3,97 & 20 & 8,25 & 0 & $x x x$ \\
\hline & Trabalhadores agropecuários, florestais, caça e pesca & 0 & $x x x$ & 9 & 9,93 & 0 & $x x x$ & 0 & $x x x$ & 0 & $x x x$ & 0 & $x x x$ \\
\hline & Trabalhadores da produção de bens e serviços industriais & 11 & 1,65 & 13 & 26,49 & 18 & 4,33 & 56 & 2,15 & 0 & $x x x$ & 0 & $x x x$ \\
\hline & Trabalhadores de reparação e manutenção & 0 & $x x x$ & 0 & $x x x$ & 0 & $\mathrm{xxx}$ & 0 & $\mathrm{xxx}$ & 0 & $x x x$ & 0 & $x x x$ \\
\hline \multicolumn{2}{|c|}{ Total 2} & 682 & & 222 & & 579 & & 200 & & 217 & & 37 & \\
\hline \multicolumn{2}{|l|}{ Total } & 3.256 & 11,52 & 571 & 27,86 & 2.074 & 28,21 & 344 & 5,02 & 1.674 & 15,70 & 200 & 16,58 \\
\hline
\end{tabular}

As conclusões anteriores se aplicam principalmente à RM de São Paulo. Na RMRJ, não há discrepância em relação às evidências acima assinaladas, embora o número de imigrantes seja bem menor e a presença de sul-americanos, europeus e africanos no comércio e serviços seja mais significativa proporcionalmente do que em São Paulo. Contudo, em se tratando de trabalhadores notoriamente de pior nível de remuneração (africanos e sul-americanos), convém observar que do total de 819 africanos que chegaram ao Rio entre 1995 e 2000, apenas 200 (24\% do total) declararam renda e ocupação. Já entre os 1.591 sul-americanos que chegaram ao Rio no mesmo período essa proporção é muito maior (42,9\%): 682 pessoas declararam renda e ocupação. A probabilidade de que haja mais clandestinos e indocumentados entre os africanos deve ser bem maior do que entre os sul americanos. Os dados da RMSP mostram conclusão similar: entre os nascidos na América do Sul que chegaram entre 1995 e 2000, 54,5\% declararam ocupação e renda na semana anterior 
ao Censo, já entre os nascidos na África (onde os angolanos predominam) apenas 39,5\% declararam ocupação e renda.

\section{Conclusões e considerações finais}

Até hoje, milhões de pessoas ainda são forçadas a migrar por uma série de fatores mais ou menos bem conhecidos, tais como: guerras longas e sangrentos conflitos étnicos; perseguições políticas e religiosas; crises econômicas e estagnação de longa duração; grandes desequilíbrios ecológicos e comprometimento da lavoura e pecuária; ditaduras e governos autoritários que sufocam a liberdade de escolha da população; corrupção generalizada e ausência de empregos para os não apaniguados do poder.

Algumas grandes cidades funcionam como uma espécie de âncora para os imigrantes internacionais expulsos de seus países de origem, desesperançados do futuro em suas antigas comunidades dilaceradas pela pobreza e piora das condições de vida. Dados indicam que cidades de grande tamanho oferecem maiores oportunidades de sobrevivência a esses migrantes, embora não se trate de uma dedução linearmente lógica, uma vez que existem esferas jurisdicionais nas quais a soberania dos Estados e a xenofobia podem colidir com o interesse puramente econômico de se explorar um tipo de mão de obra que procura sobreviver a qualquer custo, mesmo na clandestinidade e sob a ausência de direitos elementares.

Contudo, mesmo se tratando de uma cidade mundial no capitalismo globalizado, Nova York estabelece um paradigma nessa discussão ao indicar que não é estritamente o fator econômico que explica a preferência dos imigrantes internacionais ao procurá-la como pouso seguro. Metha nos faz pensar na importância de fatores extraeconômicos que estruturam a vida de comunidades interétnicas apoiadas por redes sociais migratórias e pela alteridade, pluralismo e tolerância que "pairam" no ar de uma grande metrópole onde as desigualdades econômicas permanecem altas.

Esse artigo sugere que a expansão da aceitação do outro seja um indicador de democracia direta, algo similar ao que denominamos expressões virtuosas de "democracia territorial" na vida urbana atual. Nessa direção, cabe refletir sobre a expansão conceitual do que se entende por necessidade básica, de modo a incorporar às necessidades socioeconômicas um conjunto de necessidades geoculturais derivadas da cidadania que o humanismo evoca, o que incluiria direitos elementares e cidadania; relações de pertencimento; liberdade e confiança entre pessoas 
e comunidades. Liberdade não estritamente nos termos de Amartia Sen quando propõe ser ela um pré-requisito para o desenvolvimento ${ }^{13}$, pois a expansão da democracia formal auxilia, sim, no combate à pobreza e na redução das desigualdades econômicas, mas não é suficientemente capaz de vencer dificuldades sistêmicas geradoras de novos pobres no atual capitalismo financeiro globalizado.

De todo o modo, a maior ou menor receptividade do imigrante internacional pode ser vista como um indicador não convencional de democracia. E tanto as evidências históricas quanto dados contemporâneos retratam as grandes cidades como territórios nos quais a pluralidade e a tolerância são mais substantivas, a despeito dos interesses econômicos que permeiam a exploração da mão de obra migrante.

No Brasil, os dados amostrais do Censo 2000 permitem estabelecer conclusões que convergem em certa medida, com o exemplo de Nova York, sobretudo quando são focalizadas as duas maiores metrópoles do país, São Paulo e, secundariamente, Rio de Janeiro. O tamanho urbano tem importância assim como o passado migratório e as leis nacionais mais ou menos restritivas em certos momentos históricos. A larga tradição migratória inscrita na formação das três metrópoles supracitadas constitui um traço comum entre elas, principalmente se cotejadas as megacidades de São Paulo e de Nova York, onde o desenvolvimento econômico foi muito intenso em distintos períodos do século XX.

Nas duas maiores metrópoles brasileiras, ao que tudo indica, imigrantes legais provenientes de países com uma longa história de desenvolvimento econômico estão mais habilitados a usufruir de ocupações de altas remunerações. Contudo, há também entre essas nacionalidades de origem uma expressiva quantidade de trabalhadores de menor renda (aferidos por histogramas e desvio padrão aqui não apresentados). Tais rendimentos, entretanto, se situem muito acima da renda média dos imigrantes pobres que vieram da África e América do Sul. As principais conclusões da análise dos dados ressaltam que:

- maior tamanho urbano-demográfico constitui um fator explicativo da elevada presença de imigrantes internacionais nascidos em um número maior de países. A forte disparidade entre os números das RMs de São Paulo e Rio de Janeiro sinaliza para um grau maior de receptividade de imigrantes na RMSP;

\footnotetext{
${ }^{13}$ SEN, Amartia. Desenvolvimento como Liberdade.
} 
- o fator "distância" e oportunidades econômicas explicam a presença majoritária de imigrantes internacionais naturais da América do Sul nas duas RMs;

- sucessivas gerações de imigrantes estrangeiros estruturam correntes e contracorrentes migratórias identificadas em parte dos dados censitários, o que define preferências por determinados destinos de acordo com as nacionalidades de origem;

- a discriminação intercontinental dos imigrantes estrangeiros indica que a seletividade pela origem atua nas condições de vida dessas subpopulações. Os provenientes da África e da América do Sul são mais pobres e menos ocupados no mercado de trabalho das RMs de São Paulo e Rio;

- Os imigrantes indocumentados e clandestinos parecem ser relativamente numerosos e boa parte não aufere renda resultante do trabalho formal.

Esse texto é ainda um trabalho inicial que introduz uma série de questões que perpassam o conceito de democracia territorial, tendo como base os destinos urbanos dos imigrantes internacionais. Há muito ainda a ser explorado dentro dessa perspectiva e, se considerarmos os efeitos cumulativos da imigração internacional, os dados do Censo de 2010 certamente permitirão explorar mais profundamente o conjunto de evidências aqui apontadas e introduzir novas perguntas e questões relativas aos temas aqui assinalados.

\section{Bibliografia}

BAGANHA, Maria loannis. "A cada sul o seu norte: dinâmicas migratórias em Portugal", in SANTOS, Boaventura S. A globalização e as ciências sociais. São Paulo: Cortez, 2005.

BELLI, Benoni. A politização dos direitos humanos. São Paulo: Perspectiva, 2009.

BIGNOTTO, Newton. "Problemas atuais da teoria republicana", in CARDOSO, Sérgio (org.). Retorno ao republicanismo. Belo Horizonte: Editora UFMG, 2004. BOBBIO, Norberto. A era dos direitos. Rio de Janeiro: Editora Campos, 2004.

BRITO, Fausto. A ruptura dos direitos humanos na filosofia política de Hannah Arendt, CEDEPLAR. Textos para a discussão 402. Belo Horizonte, 2010.

CANOTILHO, Joaquim Gomes (org.). Direitos Humanos, Estrangeiros, Comunidades Migrantes e Minorias. Oeiras: Celta Editora, 2000.

CASTRO, Mary Garcia. "Migrações internacionais e direitos humanos e o aporte do reconhecimento", in REMHU: Revista Interdisciplinar da Mobilidade Humana. Brasília, DF, v. 16, n. 31, 2008, p. 7-36. 
HABERMAS, Jürgen. "Três modelos normativos de democracia", in Lua Nova, n. 36, 1995.

MARTINE, George et alii. "A urbanização no Brasil: retrospectiva, componentes e perspectivas", in Para a década de 90; prioridades e perspectivas de políticas públicas. Brasília: IPEA/IPLAM, 1990.

MARTINE, George; PELIANO, José Carlos. "Diferenciais Migratórios: Resultados e Implicações", in MARTINE, George, PELIANO, José Carlos. Migrantes no Mercado de Trabalho Metropolitano. Brasília: IPEA/IPLAN, 1978, p. 161-189.

MARTINE, George. "Adaptação dos migrantes ou sobrevivência dos mais fortes?", in MOURA, Hélio A. de. Migração interna textos selecionados. Fortaleza: Banco do Nordeste do Brasil, 1980, p. 949-947.

MATOS, Ralfo. Geografia da População. Belo Horizonte: Editora UFMG, 2011.

. "Notas sobre democracia territorial e espaços urbanos dispersos", in Workshopp sobre Cidades Médias Brasileiras, 2009, CD Rom, p. 1-19.

MENDES, Maria M. "Resenha de Livro", in Análise Social, n. 167, v. XXXVIII, 2003. METHA, Suketu. "Cidade Nua", in Folha de S. Paulo; Cad. Ilustríssima, 11 set. 2011. REIS, Rossana Rocha. "Soberania, Direitos humanos e migrações internacionais", in Revista Brasileira de Ciências Sociais, v. 19, n. 55/junho, 2004, p. 149-164.

SEN, Amartia. Desenvolvimento como Liberdade. São Paulo: Companha das Letras, 2002.

WERLE, D. Luís. "Democracia Deliberativa e os Limites da Razão Pública", in SCHATTAN, Vera; NOBRE, Marcos (orgs.). Participação e Deliberação. São Paulo: Editora 34, 2004, v. 1.

\section{Abstract}

\section{Migration as an indicator of democracy, economic survival and special basic needs}

This work presents considerations and evidence about the inclusion of foreign populations in metropolitan areas. It is assumed that the acceptation of the other is an indicator of "territorial democracy". In Brazil, the Census 2000 enables to identify certain ethnic tolerance in relation to foreign migrant, as pointed out by Mehta for New York. São Paulo and Rio de Janeiro, because of their own size, shelter a wide variety of national origins in international migration, although there is a high variation in income levels and types of occupation.

Keywords: Migration; Territorial Democracy; Ethnic Tolerance.

Recebido para publicação em 11/10/2011.

Aceito para publicação em 26/01/2012. Received for publication in October, 11 1 th, 2011. Accepted for publication in January, $26^{\text {th }}, 2012$. 